\title{
A Formação Do Espaço Urbano Da Cidade De Belo Horizonte: Um Estudo De Caso À luz De Comparações Com As Cidades De São Paulo E Rio De JANEIRO
}

DANiela PASSOS ${ }^{1}$

\begin{abstract}
Resumo
O presente trabalho procura analisar como se constituiu o espaço urbano e social da cidade de Belo Horizonte, no final do século XIX e início do século XX, à luz de comparações com as cidades de São Paulo e Rio de Janeiro no mesmo período. Inaugurada em 1897, a nova capital mineira se tornou a primeira cidade planejada do país. O objetivo deste ensaio é o de explicitar como as ideias republicanas inspiraram à experiência urbanística da cidade, seu aspecto modernizante e ao mesmo tempo sua estratificação social, que classificava e hierarquizava o território belorizontino, no intuito de assegurar as condições de vida para uma população em rápido crescimento, adequando a cidade aos negócios e criando mecanismos de controle social para a uma população carente e trabalhadora de Belo Horizonte.
\end{abstract}

Palavras-chaves: Belo Horizonte. Estado. São Paulo. Rio de Janeiro

\section{Belo Horizonte's Urban Space Formation: A Study \\ Illuminated by the comparisons with the cities of São Paulo AND Rio de JANEIRo}

\begin{abstract}
This article seeks to analyze how the urban space and urban social city of Belo Horizonte was constituted, in the late 19th and early 20th century. For doing so,

1 Doutora em Sociologia pela Universidade Federal de Minas Gerais, Brasil. Mestre em História pela Universidade Federal de Ouro Preto (UFOP), Brasil. ddanipassos@gmail.com
\end{abstract}


we bring to light some comparisons with the cities of São Paulo and Rio de Janeiro in that same period. Created in 1897, the new capital became the first planned city in Brazil. The goal of this essay is to clarify how the Republican ideas inspired the city's urban experience, its modernizing aspect and at the same time its social stratification, which classified and put hierarchy logics in the industrial territory of Belo Horizonte, in order to ensure the conditions of life for a rapidly growing population, adapting the city to business and creating social control mechanisms for a needy and hard-working population.

Keywords: Belo Horizonte. State. São Paulo. Rio de Janeiro

\section{INTRODUÇÃo}

Considerando a cidade como um espaço que passa por processos de constantes transformações, cuja origem se confunde com a própria sociedade que ali se estabelece (ou mesmo precede o centro urbano em expansão), podemos afirmar que o ambiente citadino torna-se, pois, a um só tempo, gerado e gerador de novas formas de relações sociais.

Pensar a cidade é, acima de tudo, entender o que existe entre os elementos contrários que compõem a trama dos diversos confrontos sociais. O próprio espaço urbano tende a denunciar a existência de uma possível tensão intrínseca em sua mudança. Neste caso, o urbano pode ser tido como obra histórica, que se produz continuamente a partir das contradições inerentes da sociedade. No caso da "cidade progresso" o que se vê é um cenário de amplas avenidas, praças arborizadas, espaços comerciais, cafés, construções imponentes, asfalto, enfim, uma série de artifícios que procuram condicionar o homem moderno a atitudes e comportamentos previsíveis e padronizados. A cidade moderna reinventa e ressignifica caminhos antes tidos como tortuosos, impondo um ritmo de vida diferenciado e comportamentos que são próprios do processo de modernização. Entretanto, o impacto visual da cidade moderna, forjada a partir de projetos políticos modernizantes (como plantas, mapas, códigos de posturas, entre outros), não é capaz de 
apagar as vivências e as sociabilidades antes experimentadas nestes espaços já transformados (LOPES, 2010).

Conhecer o processo de construção da cidade de Belo Horizonte se faz importante para entendermos as especificidades que diferenciam o seu processo de formação histórico/social das demais capitais do país (entre elas podemos citar as cidades do Rio de Janeiro e São Paulo). Belo Horizonte também se tornou um local de segmentação, que hierarquizou seu território e expulsou para a área suburbana e rural as camadas populares, incluindo os trabalhadores.

De tal modo, é necessário ter em mente que o projeto da cidade e as medidas tomadas para sua completa implantação devem ser entendidos dentro do seu tempo, numa visão de valorização do racional e para uma capital que se pretendia modelo dentro do "Estado republicano".

No que se refere à metodologia da pesquisa, primeiramente foram delineadas as obras bibliográficas relacionadas ao estudo teórico, foco desta pesquisa. A mesma foi guiada por temas que envolvem o contexto sobre a construção do espaço sócio urbano da cidade de Belo Horizonte à luz de comparações com os projetos de urbanização das cidades de São Paulo e Rio de Janeiro em fins do século XIX e início do século XX.

Outros documentos também foram estudados, visando complementar este trabalho, principalmente os documentos relacionados à construção da cidade de Belo Horizonte, sendo eles produzidos pela Superintendência de Desenvolvimento da Região Metropolitana de Belo Horizonte, os Anais do Conselho Deliberativo da capital, documentos estes produzidos pelo poder público da cidade de Belo Horizonte, disponíveis no Arquivo Público da Cidade de Belo Horizonte (APCBH) e parte da documentação produzida pela Comissão Construtora da Capital, disponível para pesquisa no Arquivo Público Mineiro (APM). 
Assim, o objetivo deste artigo é o de pensar como o aspecto disciplinar e a imagem do moderno marcaram a construção do espaço urbano e social da cidade de Belo Horizonte tendo, à luz de comparações, os modelos urbanísticos das cidades de São Paulo e do Rio de Janeiro, para entendermos o contexto histórico do surgimento da nova capital mineira.

\section{A Construção Da Cidade De Belo Horizonte: Formação Urbana E Espacial}

A cidade de Belo Horizonte foi construída pela intervenção estatal, num traçado modernizador, inspirado nas experiências urbanísticas das cidades europeias e norte-americanas, ou seja, tratase de uma cidade planejada. Segundo Letícia Julião (1996, p. 51), a criação e a construção da cidade concretizavam os desejos de uma elite que encarava o advento da República como sinal de ruptura com o passado, preconizando a modernização e o desenvolvimento nacional.

As novas ideias, surgidas com o advento da República, vieram afetar diretamente a vida política do país, já que poderiam significar o rompimento com o sistema político centralizador exercido pelo governo imperial. Oambiente de incertezas dos primeiros anos do novo regime político, em meio à necessidade de legitimação, determinou um horizonte favorável a um ousado projeto de construção de uma cidade capital (CARVALHO, 1987).

O ideal de modernização foi de fundamental importância para se pensar uma nova cidade capital, uma nova territorialidade para sede do governo do Estado de Minas Gerais. A modernização, atingido as áreas econômicas, políticas e sociais e o modernismo englobando a arte, a cultura e a sensibilidade foram fatores chaves para se pensar um novo espaço para a capital mineira, agregando, assim, todo o simbolismo de uma época (fins do século XIX e início do século XX). 
Movido pela nova ordem republicana, positivista e científica, e inspirado ainda em um repertório urbanístico em alta no estrangeiro, o engenheiro chefe da Comissão Construtora da nova Capital, Aarão Reis (atendendo ao governo da época) planejou a cidade concebendo as ruas como "artérias e veias" (SENNETT, 2006). O planejamento das cidades, durante o século XIX, assentou-se em ideais sanitaristas, comparando-as a um corpo saudável, limpo e onde o movimento se dava com total liberdade. Com isso, a população poderia respirar livremente, numa cidade altamente organizada e compreensiva, em que ruas, avenidas e praças representassem uma ruptura radical com o modelo das cidades até então existentes.

As cidades planejadas, ainda segundo Richard Sennett (2006), eram pensadas de acordo com a revolução científica da compreensão do corpo humano e de sua circulação sanguínea, proposto por William Harvey em sua obra de 1628, De motu cordis. O que Harvey expôs parecia bastante simples: o coração bombeia sangue através das artérias e veias, recebendo-o das veias, para ser bombeado. Muitos engenheiros e urbanistas fizeram tal analogia na construção de cidades: a livre circulação (como a sanguínea) ao longo das ruas principais, transformando-as num importante espaço urbano, cruzando áreas residenciais ou atravessando o centro da cidade.

Construtores e reformadores passaram a dar maior ênfase a tudo que facilitasse a liberdade de trânsito das pessoas, imaginando uma cidade de "artérias" e "veias" contínuas, através dos quais os habitantes pudessem se transportar, tais como hemácias e leucócitos no plasma saudável. Assim, as palavras "artérias" e "veias" entraram para o vocabulário urbano já no início do século XVIII, aplicadas por projetistas que tomaram o sistema sanguíneo como modelo para o tráfego, quando muitos engenheiros estabeleceram uma ligação entre saúde, locomoção e circulação. 
Belo Horizonte não fugiu a estes ideais. Segundo o artigo n.2, do decreto de n.803 do ano de 1895, sobre o levantamento da planta geral da capital, temos que: "a sua área será dividida em seções, quarteirões, lotes, com praças, avenidas e ruas necessárias para a rápida e fácil comunicação dos seus habitantes, boa ventilação e higiene" ${ }^{2}$.

Aarão Reis planejou as ruas da área central com largura de $20 \mathrm{~m}$, para a conveniência, arborização e livre circulação de veículos. Já as avenidas tiveram suas larguras fixadas em $35 \mathrm{~m}$, suficiente para dar beleza e conforto à população. E não bastava um modelo traçado somente em soluções arquitetônicas, a gestão moderna da cidade exigia intervenções das mais diversas como saberes jurídicos, médicos-sanitaristas e estatísticos, entre outros, na busca por respostas a problemas como miséria, falta de saneamento, doenças, densidade populacional e o potencial de tensões e revoltas sociais (BARRETO, 1995).

Inaugurada em 12 de dezembro de 1897, a cidade-capital representou tudo o que de moderno era preconizado, nas palavras de Joaquim Nabuco Linhares (1905, p. 381): “Hércules e titânicos foram os trabalhos então realizados. Do Nada pode-se dizer, e em tão curto espaço, surgiram as belas avenidas e ruas que aqui estão e os suntuosos edifícios públicos e particulares que garbosos sustentam nesta cidade."

Característica de uma cidade que se desejava moderna ${ }^{3}$, Belo Horizonte não fugiu ao paradigma de ser um local de segmentação. De acordo com o estilo funcional e progressista de urbanismo que se iniciou na segunda metade do século XIX, a nova capital de Minas Gerais também possuía espaços classificados e ordenados de acordo com as funções e necessidades sociais. Tal fato é percebido no projeto

2 Minas Gerais, Ouro Preto: 11/ 01/1895, p.84 (apud BARRETO, 1995, p. 232).

3 De acordo com Rogério Arruda (2000, p. 221) o termo moderno significaria um ideal de mudança, de transformação: a busca incessante de um novo tempo. 
(planta) do engenheiro Aarão Reis, que dividiu Belo Horizonte em três zonas:

\begin{abstract}
A zona urbana que constituía o espaço moderno e ordenado reservado para as elites mineiras. Possuía avenidas largas, retas, geométricas, infraestrutura sanitária e técnica, área que deveria ser espelho das cidades mais modernas do mundo; a zona suburbana, fora dos limites da Avenida do Contorno que funcionava como uma fronteira que separava a vida urbana da suburbana, onde as moradias eram sofríveis e os serviços precários; e, por fim, a zona rural, um cinturão verde, onde se localizariam os núcleos coloniais que abasteceriam a Capital de frutas, legumes, verduras e matéria prima para a sua construção (OLIVEIRA, 2004, p. 34-35).
\end{abstract}

Esta divisão funcionava como instrumento para o controle da cidade, sendo que os construtores fixaram os seus limites, classificaram e hierarquizaram os territórios, que deixaram de ser uma "dimensão indefinida" para se transformarem em áreas delimitadas e identificáveis (JULIÃO, 1996, p. 57).

O objetivo desse "enquadramento social" era estabelecer uma ordem dentro da cidade. De acordo com os construtores da cidade (lembrando que os mesmos eram influenciados pelo contexto da ordem liberal vigente), era necessário traçar com a régua e o compasso uma ordem social harmônica, unitária, onde não houvesse lugar para a chamada "desordem urbana".

Nas intervenções eram implantados sistemas sanitários públicos; abertas longas avenidas compatíveis com o tráfego denso; fincados edifícios modernos nos antigos cenários medievais. Tratava-se de assegurar condições mínimas de vida para uma população em rápido crescimento, adequar a cidade aos negócios, às instituições e ao poder burguês e, ainda, criar dispositivos de controle da multidão de homens pobres e trabalhadores, de modo a ajustá-los às exigências produtivas modernas e a um padrão de ordem urbana (JULIÃO, 1996, p. 55). 
Portanto, as cidades amplas, abertas, livres para passagens e transparentes valorizaria a individualidade. As pessoas estariam enquadradas no conjunto que foi articulado. Os espaços abertos e iluminados da cidade deveriam colocar todos sob a vista de todos. As construções das cidades e a revolução urbanística (cidades planejadas) com suas ruas largas, vastas e limpas, poderiam também tornar visíveis as pessoas que nela transitam e vivem. A cidade se tornaria uma paisagem naturalizada, palco de acontecimentos que nada opera, local que se reproduz, se filtra, se duplica ou se absorve a luz, permitindo ser visto ou se ver, conforme uma vontade alheia aos transeuntes. Sabemos que esta situação não basta para formar comportamentos, mas pode ser através dela que eles venham a se desenvolver. Por outro lado, cabe ressaltar que este sistema de ordem era característico do contexto liberal vigente no início do século $\mathrm{XX}$, onde a ideia de cidadania e individualismo era enfatizada. Neste sentido, os indivíduos, mesmo sendo "vigiados", também cumpriam a máxima da valorização do bem público, de preservação e respeito ao espaço urbano social.

Antes mesmo da inauguração da capital mineira, foi transferido da cidade de Sabará o destacamento militar que se instalou na Praça Belo Horizonte (bairro de Santa Efigênia). De acordo com os estudos da Superintendência de Desenvolvimento da Região Metropolitana, as ações das forças de segurança eram chamadas a atuar sobretudo na vila operária (Barro Preto) em incidentes (como brigas, discussões, pequenos motins, etc.) entre estrangeiros e nacionais e na dissolução de reuniões operárias de caráter reivindicatório (PLAMBEL, 1979, p. 106). Assim, para muitos, se o Estado não se excedesse em punições, seria:

[...] impossível manter a ordem naquele meio excepcional de Belo Horizonte, com os seus 5.000 operários de todas as nacionalidades, muitos desacompanhados de suas famílias e outros tantos que não as tinham, além de 
crescido número de aventureiros, de desclassificados e de malfeitores de toda espécie. Ora, aqueles homens que, durante o dia, brandiam as ferramentas, explanando o solo e construindo a cidade que aqui hoje admiramos, mal a noite caia, ajuntavam-se em tavernas, que proliferavam por toda parte como cogumelos, e aí bebendo, fumando, jogando, discutindo, armavam frequentes distúrbios. Mas bastava que surgisse ali o temido capitão Lopes e tudo serenava, pois, ele, sem nada temer, entrava nas tascas, entre os brigões, prendia-os, entregava-os aos soldados. Os raros que se revoltavam contra a sua energia pagavam caro a ousadia: recolhia-os ao xadrez de sua delegacia, depois de fazê-los saborear as doçuras dos marmeleiros do seu quintal... Por fim, até os mais valentões se submetiam à sua autoridade, passivamente, a fim de evitar a marmelada. E era assim que ele, à noite, enquanto a população ordeira dormia tranquilamente, percorria as tascas, dando ordens, repreendendo, mandando fechar portas, sempre respeitado e temido, dando margem a que os construtores da cidade pudessem trabalhar despreocupados em relação ao delicado problema da ordem pública (BARRETO, 1995, p. 351).

Desta forma, percebemos que todo e qualquer desvio da ordem original era tido como caos urbano. A intenção (ou tendência) dos construtores da nova capital mineira tornar-se-ia a de impedir as manifestações da pluralidade dos habitantes sendo estas suscetíveis de serem banidas do espaço citadino. Na cidade capital mineira nada poderia ser mais atraente do que um espaço modelar, disciplinado, com conceitos e condutas traçados para que se revelasse tudo e ensinasse como as relações entre coisas e pessoas deveriam ser.

Polo civilizacional; centro poderoso; irradiadora de energia, fortaleza, beleza e vitalidade ${ }^{4}$; vetor de desenvolvimento econômico e cultural; espaço para a celebração do futuro e para a exibição das conquistas da modernidade; vitrines da civilização. Estas são algumas

4 Estes termos aparecem no jornal A Gazeta de Ouro Fino no contexto de debates sobre a mudança da capital de Minas Gerais. A Gazeta de Ouro Fino, 25 dez. 1892 (apud ARRUDA, 2011). 
representações sobre o que se esperava e de como se via uma cidade capital na segunda metade do século XIX, em várias partes do mundo (ZUCCONI, 2009, p. 29).

Esta experiência, ao que parece, não é algo incomum no Brasil e nem em outros países da América Latina, de modo que podemos acreditar que esses modelos urbanos estão diretamente relacionados ao processo de expansão capitalista do final dos Oitocentos. Nesse período de profundas transformações políticas e econômicas internas e externas, em que estabeleciam conexões variadas com o contexto internacional, o Brasil (assim como boa parte da América Latina) se consolidava como Estado nacional e vivia os desafios da modernidade industrial capitalista. Para além da criação das novas cidades planejadas, as transformações contemplaram também projetos de remodelação urbana (ARRUDA, 2011, p. 24).

O espaço público, neste contexto de ordem liberal, segundo Richard Sennett(1989), destinava-se muito mais a ideia passagem do que de permanência. As ruas amplas seriam específicas para movimentação e circulação, uma espécie de arquitetura da visibilidade. Por ser um espaço amplo, aberto e público, acabaria por produzir um isolamento, pois todos estariam visíveis a todos, o que tornaria a liberdade do espaço um conflito com a liberdade do corpo. $\mathrm{O}$ individualismo das grandes cidades veio "amortecer" o corpo moderno, não permitindo que ele criasse vínculos. Os corpos individuais se tornaram desligados dos lugares que passaram a transitar, perdendo ainda a noção de destino compartilhado e se tornaram desencorajados a se organizarem em grupos. As cidades planejadas passariam então a funcionar como isolante do espaço; praticamente esvaziando-o, impossibilitariam as aglomerações e privilegiariam o corpo em movimento. Assim, evitarse-iam os tumultos.

Em se tratando do plano da cidade de Belo Horizonte houve uma rigidez quanto à construção do espaço, que destinava a área 
interna - perímetro da Avenida do Contorno - a funções específicas, empurrando para as zonas suburbanas e rurais as camadas populares. Isto se deu ainda pela grande dificuldade de acesso à moradia dentro da área central, que deveria ser obtida através do mercado imobiliário, que crescia juntamente com a cidade, sendo que o crescimento populacional se deu da periferia para o centro.

É importante salientar que o espaço em construção da nova capital mineira visava o funcionamento eficiente do Estado, desta forma, no que se refere à ocu pação, tratava-se de atender primeiramente aos funcionários públicos oriundos de Ouro Preto (antiga capital de Minas Gerais). O governo mineiro cederia gratuitamente um lote de terreno na nova capital, de acordo com a planta geral, para cada um dos funcionários estaduais que por força de suas funções fossem obrigados a transferir-se para Belo Horizonte; e aos proprietários de casas em Ouro Preto que pagassem o imposto predial no exercício do ano de 1890 e que construíssem suas novas residências até o prazo de 17 de dezembro de 1893 (BARRETO, 1995, p. 238). Esta foi uma das formas encontradas pelo governo para vencer a resistência dos que não queriam a mudança.

No bairro Funcionários abrigou-se o funcionalismo público. Tal localidade se constituiu em uma espécie de "cartão de visitas", pois possuía excelentes casas, ruas simétricas (como em todo traçado, dentro da chamada área urbana) e ótimas instalações sanitárias. Porém, é importante destacar que mesmo neste bairro havia a convivência vertical entre classes sociais, pois abrigava funcionários públicos em geral, desde desembargadores a servente de escolas (COSTA; BAPTISTA, 1998, p. 263). Por sua vez, a área central foi destinada à construção de prédios públicos, do Parque Municipal e da Zona Comercial (atualmente conhecida como Rua Santos Dumont).

Assim, a área central era considerada a mais "atraente", pois concentrava os serviços urbanos modernos como saneamento e 
iluminação. Obviamente, por ser o território mais elegante era o menos acessível, já que seus terrenos eram bem valorizados (pelos padrões de mercado da época). Portanto, a área central, especificamente o bairro Funcionários e as partes altas, próximas às ruas "Bahia", "Rio de Janeiro" e "Espírito Santo", acabou se tornando o lugar das elites, que construíram suas residências, faziam negócios e desfrutavam do lazer. Os pobres também estavam localizados na área central, porém ficavam restritos apenas ao Barro Preto, ao bairro do Quartel (atualmente conhecido como bairro de Santa Efigênia) e ao bairro do Comércio (atual Hipercentro, ou Centro da cidade).

Depois desta análise da cidade de Belo Horizonte, cabe fazermos uma abordagem comparativa do processo de urbanização das cidades de São Paulo e Rio de Janeiro. Assim, conseguiremos perceber o quanto que a cidade de Belo Horizonte teve de especificidades em sua formação, e como a atuação do poder público foi significativa para a construção da cidade capital mineira.

\section{A construção do espaço urbano nas cidades de São Paulo e Rio DE JANEIRO EM FINS Do SÉculo XIX E INício do SÉculo XX.}

No fim do século XVI, a cidade de São Paulo continha mais ou menos 120 casas, amontoadas no alto do morro. A vida rural era mais importante: o local preferencial de moradia era a fazenda; a casa da cidade era mero alojamento para visitas temporárias. O planalto paulista tinha sua base econômica na agricultura de subsistência. $\mathrm{O}$ descobrimento do ouro, nos fins do século XVII, em nada auxiliou o desenvolvimento da vila. Pelo contrário, muitos paulistas migraram para as zonas de mineração. De outro lado, rotas fluviais e terrestres foram se desenvolvendo entre São Paulo, Minas Gerais e Mato Grosso, fazendo de São Paulo um entreposto comercial. Em 1765, a população 
foi estimada em 6 a 7 mil habitantes, incluindo aí os escravos (1970). Em 1836, a população da cidade alcançava cerca de 22 mil habitantes:

A posição econômica da cidade mudou com a expansão da cultura do café na província de São Paulo. A primeira zona a ser favorecida pela produção intensiva do café foi o vale do Paraíba, tributária do Rio de Janeiro. Dado o rápido e constante aumento das plantações de café após a Independência, a lavoura cafeeira expandiu-se para o noroeste da capital. Essa nova região apresentava certas vantagens em relação ao vale do Paraíba: não era montanhosa, possuía grandes faixas de terras roxas, extremamente favoráveis à plantação do café. Para a cidade de São Paulo, a importância desse deslocamento territorial da cafeicultura foi crucial: um vasto e rico interior agrícola tornava-se tributário da capital e de seu porto, Santos. A partir de 1867, ano em que foi implantada a primeira ferrovia na cidade, interligando Santos e Jundiaí, seus vales foram sendo atravessados por ferrovias. A capital aumentou sua população para cerca de 32 mil moradores em 1870, dos quais um terço era escravo. Entroncamento ferroviário, sede de uma província em plena expansão, a cidade passava por uma importante transformação urbanística, social e econômica (CARVALHO; PASTERNAK; BÓGUS, 2010, p. 302-303).

Assim, do núcleo provinciano, considerado de "segunda categoria", antes de 1870, a cidade de São Paulo passou à condição de centro da região economicamente mais dinâmica do país. A "capital do café", durante o período denominado de República Velha, despontou do impulso agroexportador, iniciando ainda um centro fabril, que em meados do século $X X$, já era conduzida a estágio de metrópole industrial (CAMPOS, 2002, p. 17). Assim, a perspectiva da construção de um centro urbano de porte, no lugar da "cidadezinha" modesta, existente até então, passou a implicar a emergência de propósitos centralizadores e expansionistas amparados na ideia da modernização (como em Belo Horizonte) da região paulistana. 
Sem dúvida, o marco divisor para o crescimento da cidade de São Paulo foram os anos da década de 1870, onde houve um impulso da comercialização e do plantio do café. Tal fato levou a reestruturação do espaço, baseado principalmente na criação de canais de exportação e interiorização do território paulista. O sistema ferroviário passou a fazer uso de um corredor de escoamentos desembocando no porto da cidade de Santos. Desta forma, a concentração do fluxo comercial sobre o eixo São Paulo-Santos teria enorme impacto sobre o crescimento da capital paulista.

Nesse momento, e em especial a partir da década de 1870, a cidade passa a conviver com intensas mudanças socioeconômicas, demográficas e urbanísticas, em meio à prosperidade crescente das exportações cafeeiras do chamado "Oeste" paulista, à implantação da ferrovia e à crise final da escravidão no país. Esse conjunto de fatores conflui para caracterizar a urbanização paulistana de fins do XIX. Ela implica uma alteração das funções dos espaços da cidade em favor de um maior controle e racionalização, de modo a assegurar para São Paulo o status de entreposto comercial e financeiro privilegiado para as relações entre a lavoura cafeeira paulista e o capital internacional (FREHSE, 2001, p. 170).

Por conta da expansão cafeeira, nos anos de $1872-1875^{5}$ o governo de São Paulo (chefiado pelo presidente da província, João Teodoro Xavier - nomeado pelo partido conservador do gabinete do Visconde Rio Branco), criou condições para expansão urbana. $\mathrm{O}$ objetivo era transformar a cidade de São Paulo em polo de atração comercial. Para além do sistema de transportes e a expansão cafeeira, a cidade tornava-se polo administrativo, centro residencial, financeiro e de negócios. As intervenções realizadas visavam remodelar os espaços públicos, tornando-os mais atraentes, criar novos bairros destinados a receber o afluxo populacional e estabelecer ligações viárias entre os

5 Período que também ficou conhecido como a "segunda fundação" de São Paulo por ser um momento de grande intervenção pública no processo de urbanização da capital paulista. 
diversos componentes da nova ordem urbana: centro de negócios, áreas residenciais, estações ferroviárias (CAMPOS, 2002, p. 47).

[...] Entre as obras de embelezamento e lazer, João Teodoro abriu novos caminhos e reformou outros, incluindo a cidade antiga num sistema viário que preservava o seu centro ao mesmo tempo em que ordenava um anel de circulação externa ao Triângulo, potencializando futuras ocupações no que até então era apenas uma periferia vazia. O investimento na facilitação de locomoção dentro da cidade nesses anos parece, assim, ter sido muito mais um dos aspectos de uma política de expansão, que procurava incentivar a ocupação futura das áreas periféricas da capital, do que uma necessidade premente da população (AZEVEDO, 2009, p. 95).

Contudo, cabe ressaltar, que foi somente no período republicano (fins do século XIX e início do século XX) que o projeto de urbanização da cidade de São Paulo tornar-se-ia prioridade, assim como nas cidades do Rio de Janeiro e Belo Horizonte.

Em comparação com Belo Horizonte, a cidade de São Paulo teve em seu traçado urbano um aspecto de formação mais "autônoma". Os urbanistas Vítor Freire, Saturnino de Brito e Ricardo Severo (responsáveis pela remodelação urbana da cidade paulista), mesmo tecendo elogios aos empreendimentos de Aarão Reis e sua equipe no processo de construção da cidade de Belo Horizonte (onde havia se priorizado a circulação urbana, bulevares largos e arborizados, rodeados de edificações higiênicas), procuraram construir um caminho próprio para a cidade de São Paulo, não subordinado às ideias de "haussmannianas"' adotadas pelos engenheiros chefes de Belo Horizonte e do Rio de Janeiro.

6 As ideias de haussmannização se referem à reforma urbana realizada em Paris durante o Segundo Império (1853-1870) por ordem de Napoleão III e sob a direção do Prefeito do Sena Georges-Eugène Haussmann. Esta reforma urbana representa o conjunto das obras realizadas em Paris e define uma forma de intervir no espaço urbano, remodelando-o de forma "intensa e radical". 
No processo de urbanização e remodelação da cidade de São Paulo, mesmo havendo ações de caráter higienistas, de controle e disciplina da população mais pobre, através de medidas sanitárias (a exemplo de Belo Horizonte e bem ao estilo de Hausmann) ${ }^{7}$, o que prevaleceu foi a intenção de transformar a capital paulista numa "vitrine condigna para a economia cafeeira" (CAMPOS, 2002). Ou seja, mesmo havendo intervenções estatais no plano urbanístico da cidade paulista, o liberalismo predominante na condição dos negócios agroexportador também interviu no processo de urbanização da capital paulista ${ }^{8}$, o que diferencia seu processo urbanístico (mesmo que parcialmente) do que ocorreu em Belo Horizonte, onde o poder público foi mais incisivo e decisivo na construção da capital mineira.

Desta forma, durante o processo de remodelação do espaço e urbanização na cidade em São Paulo:

Qualquer processo de tomada de decisões, definição da política estatal, ou tentativa de impor um "consenso" indicando o caminho a ser seguido, envolvia a disputa entre visões divergentes, ecoando a disparidade dos interesses em jogo. Tal situação ressoava na esfera municipal, uma vez que o processo de intervenção urbanística, longe de ser mero campo de progresso técnico, implicava opções com sérias consequências sobre as condições de vida, acumulação e produção vigentes no centro urbano (CAMPOS, 2002, p. 283).

7 No mesmo espírito sanitarista e disciplinador (adotado pelas cidades do Rio de Janeiro e mais especificamente em Belo Horizonte), a Câmara paulistana reformou a Polícia Sanitária Municipal, a cargo da Intendência de Polícia e Higiene - com poderes para inspecionar prédios comerciais e de moradia (visando particularmente os cortiços - moradias populares) exigir reformas e demolições, desinfetar habitações e vacinar a população (CAMPOS, 2002. p. 62).

8 Os serviços públicos da capital paulista eram financiados, em grande parte pelo erário provincial, depois estadual. Ora, o café fez aumentar bastante a receita provincial de São Paulo, a qual em 1836 não passa de 292 contos, alcançando 489 contos em 1851, mas saltando para 1.420 contos em 1871, para 2.506 em 1876, para 3.520 em 1881 e para 5.700 contos em 1886. Em 15 anos, de 1836 a 1851 a receita paulista aumentou de $68 \%$; nos 15 anos de 1871 a 1886 de maior surto cafeeiro, o crescimento da receita foi de 300\% (SINGER, 1968, p. 39). 
Concluindo, o que se percebe, se comparado com a cidade de Belo Horizonte, é que na cidade de São Paulo, devido ao comércio agroexportador do café, na formação social e urbana da cidade, houve poucas medidas intervencionistas do poder público em seu traçado urbanístico. Não eram apenas as implicações técnicas do progresso urbano que estavam em jogo. Outras situações também estavam em fase de desenvolvimento na capital paulista como a acumulação e produção econômica e as condições de vida não apenas da população de baixa renda, mas também (e principalmente) da elite paulista em formação. Em Belo Horizonte, ao contrário, o poder público foi mais incisivo na criação do espaço urbano da nova capital mineira.

Em se tratando da capital federal, a cidade do Rio de Janeiro também passou por um intenso processo de urbanização e remodelação de seu espaço no início do XX. Na verdade, com o advento da República, a cidade fluminense sofreu grandes modificações tanto no aspecto econômico, como também nos aspectos social, político, cultural e claro, urbanístico, que já vinham sendo processados desde meados do século XIX, mas que somente puderam ganhar a devida força com a mudança de regime político.

A reforma urbana, ocorrida na cidade do Rio de Janeiro entre os anos de 1903 e 1906, teve dois tipos de intervenções: uma conduzida pelo governo federal e projetada pelo ministro Lauro Müller e o engenheiro Francisco Bicalho (principalmente focando a modernização do porto do Rio de Janeiro) e a outra levada a cabo pela prefeitura do Estado, por meio do prefeito Francisco Pereira Passos (ficando conhecida como reforma Pereira Passos). Ambos os projetos de intervenção urbana resultaram da iniciativa do então Presidente da República Rodrigues Alves que, desde o seu discurso de posse, anunciara uma grande ação de reformulação urbana, sob o pretexto de melhorar a imagem, a sanidade e a economia da capital federal, a fim de facilitar a imigração de estrangeiros ao Brasil (AZEVEDO, 
2003, p. 41), além de dar visibilidade e concretude ao ideal da então República instaurada.

A remodelação urbana da capital federal consistiu fundamentalmente na abertura, prolongamento e alargamento de um conjunto de ruas da cidade, modificando assim o sistema viário da urbe. Semelhante ao que ocorreu na cidade de Belo Horizonte, o projeto de reestruturação da cidade do Rio de Janeiro visava um centro urbano organicista. Ou seja, os engenheiros, responsáveis pelo projeto de remodelação da cidade, idealizavam a urbe fluminense como um "corpus continente de diversos órgãos vitais, sendo a ligação das ruas fundamentais para o funcionamento harmônico do corpo urbano." (AZEVEDO, 2003, p. 53)

O ideário de civilização presente no processo urbanístico de Pereira Passos era atinente a uma série de valores desenvolvidos pela sociedade europeia (belle époque) ao longo da modernidade. Consistia na manutenção de uma civilidade urbana burguesa - na qual a ideia de individualidade e de uso regulamentado do espaço público se ligava a atividade estética e cultural, na reverência a um passado e no respeito à lei e à ordem pública estabelecida pelo Estado e através de uma elite política ilustrada.

Como resultado, o governo carioca de então passou a estabelecer uma série de medidas proibitivas, que tinham a intensão de promover uma nova ética urbana, novos usos e costumes considerados condignos com os padrões daquilo que se julgaria civilizado. Ser civilizado em uma grande cidade seria, sobretudo, ter posturas pertinentes ao senso de individualidade, ao reconhecimento da legitimidade do espaço privado e principalmente da percepção do espaço público como um espaço que deve ser utilizado a partir da observação às regras estabelecidas por leis. No entanto, longe do universo de práticas e formas de uso do espaço urbano pelas camadas populares, as normas "civilizadoras" decretadas pela municipalidade 
tinham como referência os padrões burgueses de países como França e Inglaterra, exemplos máximos do que a prefeitura do Rio de Janeiro entendia por civilização.

\begin{abstract}
Assim, tal fato atribuía a esse conjunto de normas reguladoras da ética urbana uma dimensão quixotesca, pois tentava-se impor um padrão de civilidade urbana burguesa e europeia a uma cidade de tradição escravista e culturalmente heterogênea - marcada pela presença de uma miríade de migrantes e imigrantes. Nesse período, o espaço público do Rio de Janeiro era ocupado por figuras como capoeiras, ex-escravos biscateiros - muitos dos quais foram negros ao ganho antes da abolição -, carroceiros, vendedores de perus, de vísceras, de leite retirado diretamente da vaca, trapeiros, rezadeiras, tatuadores, entre outros. Como cidade tropical e de tradição escravista, era comum ver-se nas ruas estreitas e sinuosas do Rio de Janeiro o contraste entre os "cavalheiros" cariocas trajados de paletó, dividindo o espaço com negros descalços e sem camisa, anunciando aos gritos seus serviços e produtos. Somava-se a este cenário a presença de migrantes e imigrantes de diversas partes - quase sempre rurais - do Brasil e do mundo em roupas surradas e não raro de pés descalços (AZEVEDO, 2003, p. 62).
\end{abstract}

No que se refere ao contingente demográfico da cidade do Rio de Janeiro, de acordo com José Murilo de Carvalho (1987, p. 16), as alterações quantitativas foram impressionantes. Alterou-se não apenas o número de habitantes, mas também sua composição étnica e de estrutura ocupacional. A abolição da escravatura, no ano de 1888, lançou o restante da mão de obra escrava no mercado de trabalho livre e engrossou o contingente de subempregados e desempregados. Além disso, provocou um êxodo para a cidade proveniente da região cafeeira do estado do Rio de Janeiro e um aumento na imigração estrangeira, especialmente de portugueses. A população, em termos absolutos, quase dobrou entre 1872 e 1890, passando de 266 mil para 522 mil.

Ainda de acordo com José Murilo uma consequência importante a ser ressaltada deste grande contingente populacional 
foi o acúmulo de pessoas em ocupações mal remuneradas ou sem ocupações fixas. Domésticos, jornaleiros, trabalhadores em ocupações mal definidas, poderiam chegar a mais de 200 mil em 1906, vivendo em tênues fronteiras entre a legalidade e ilegalidade, por vezes participando simultaneamente de ambas.

Esta população poderia ser comparada às classes
perigosas ou potencialmente perigosas de que se falava na
primeira na primeira metade do século XIX. Eram ladrões,
prostitutas, malandros, desertores do Exército, da Marinha
e dos navios estrangeiros, ciganos, ambulantes, tropeiros,
criados, serventes de repartições públicas, engraxates,
carroceiros, floristas, bicheiros, jogadores, receptadores,
pivetes (a palavra já existia). E é claro, a figura tipicamente
carioca do capoeira [...]. Morando, agindo e trabalhando,
na maior parte nas ruas centrais da Cidade, tais pessoas
eram as que mais compareciam nas estatísticas criminais
da época, especialmente as referentes às contravenções do
tipo desordem, vadiagem, embriaguez, jogo (CARVALHO,
1987, p. 18).

Desta forma, na tentativa de impor "civilidade" ao habitante da urbe, Pereira Passos foi emitindo, ao longo de sua gestão, uma série de proibições relativas a práticas urbanas comuns na cidade. $\mathrm{O}$ prefeito passou a proibir que se cuspisse na rua e nos bondes, proibiu a vadiagem de caninos, proibiu que se fizessem fogueiras nas ruas da cidade, que soltassem balóes, proibiu a venda ambulante de loterias, de exposição de carnes à venda nas ruas, também proibiu o trânsito de vacas leiteiras na cidade e andar descalço e sem camisa. (BRENNA apud AZEVEDO, 2003, p. 62). O que para uma cidade de população tão heterogênea, podemos deduzir o qual difícil foi aplicar tais leis.

Assim, reforçando o papel do centro urbano como o de lugar modelar da civilização, Pereira Passos buscou estabelecer artérias de ligações diretas do centro com todas as regiões da cidade (muito semelhante ao projeto de urbanização da cidade de Belo Horizonte). A intenção de Pereira Passos era tornar o centro da cidade um lugar 
para o convívio "civilizado", um espaço que convidaria os habitantes dos mais diversos locais do Rio de Janeiro a frequentá-lo, uma vez que seria lugar de aprendizado da ética urbana, da civilização que deveria tomar toda a cidade.

Contudo, cabe ressaltar que a reforma urbanística empreendida por Pereira Passos, foi um pouco menos conservadora do que a que foi promovida na cidade de Belo Horizonte. Isto porque, diferente de uma avenida que contornasse a cidade e servisse como "cinturão" separando a zona urbana da suburbana (a "Avenida do Contorno" em Belo Horizonte), o que houve na cidade carioca foi o estabelecimento de avenidas que ligassem a zona sul ao centro, bem como esta aos subúrbios, regiões que receberam diversas obras de melhoramento e implementações viárias, o que proporcionou uma interligação orgânica entre diversos bairros e regiões do subúrbio desta cidade. Houve assim, uma busca de tentar articular diversas regiões urbanas com o centro urbano do Rio de Janeiro, algo fundamental no projeto de integração conservadora, no qual o centro urbano da cidade aparecia como centro modelar da civilização, lugar da sua exemplaridade para os habitantes das demais regiões da urbe (AZEVEDO, 2003, p. 69).

Desta forma, podemos dizer que a reforma Pereira Passos, foi um pouco diferente do que aconteceu em Belo Horizonte. A renovação urbanística do centro carioca tentou não excluir totalmente a presença das camadas populares deste novo espaço em construção. Houve uma ligeira tentativa de integrá-las, mesmo que de maneira conservadora, ou seja, estimulando a participação da população mais carente no centro urbano, contudo, a partir de sua adesão a uma visão de mundo individualista, liberal e de comportamento ao estilo burguês europeu. Os populares, durante a reforma Pereira Passos, tiveram que deixar a cidade (o centro) e se alojarem nos subúrbios e nos morros adjacentes. O intuito do prefeito com a tentativa de integração era a de que era possível levar "civilização" ao subúrbio, pois o carioca, ao frequentar 
o centro, fosse para trabalho ou lazer, levaria de volta ao seu local de moradia a civilidade, a ética urbana e a educação estética necessária, disseminando a "civilização" por toda a cidade.

Porém, é perceptível que a reforma Passos aumentava a segmentação social e o distanciamento espacial entre os setores da população mais carente e os "nobres viventes" do centro fluminense, ao modelo do que acontecia também em Belo Horizonte. O incremento que se fez no caso da cidade do Rio de Janeiro, se comparado com a nascente capital mineira, foi a heterogeneidade da composição social na cidade carioca. Este grande contingente diverso populacional, fez com que setores da população forjassem novas realidades sociais e culturais, o que em muitos momentos manifestaram politicamente e por vezes, de forma violenta (a exemplo de algumas revoltas populares como a da Vacina - 1904). Mesmo tentando levar a "civilidade" por toda cidade, podemos perceber que as medidas impostas por Pereira Passos foram bastante difíceis de serem cumpridas.

Destarte, podemos afirmar que o processo de urbanização da cidade carioca vem ao encontro com o que foi adotado na cidade de Belo Horizonte, ou seja, o de remodelação do espaço para a então República instaurada, levando em conta o símbolo maior de ordem e progresso. O urbanismo praticado no centro da cidade do Rio de Janeiro e da nova capital mineira passou a ser o de criar um espaço limpo, circulante e principalmente disciplinado. Contudo, como visto, este ideal para o centro do Rio de Janeiro se tornou bem mais caro do que em Belo Horizonte, devido ao fato de existir uma aglomeração muito mais heterogenia de personagens na capital federal do que na então nascente cidade mineira.

Em suma, se fizermos uma comparação com o processo de urbanização da cidade de Belo Horizonte, com as cidades de São Paulo e Rio de Janeiro, podemos perceber semelhanças e diferenças entre elas. O que marca fortemente o projeto de urbanização esta pautado no 
advento do modelo político instaurado, a República (principalmente nos casos belorizontino e carioca), onde o espaço em formação serviu para concretizar um ideal de cunho político, variando a forma como o intervencionismo estatal se deu em cada um dos dois projetos de construção da cidade. Em São Paulo, a urbanização foi marcada pelo progresso do comércio cafeeiro e se deu de forma um pouco mais caótica. Todavia, nas três cidades citadas vemos um poder público controlar a população mais carente, principalmente com medidas sanitaristas e de vigília.

O espaço se tornou algo a ser dominado e domesticado. Mesmo que na cidade de São Paulo, a urbanização tenha se dado de forma mais livre do que no Rio de Janeiro e principalmente em Belo Horizonte, a disciplina era imposta aos habitantes da cidade, seja através do intervencionismo estatal na modelação do espaço (Belo Horizonte e Rio de Janeiro), seja regulada pelo tempo e pelo ritmo do trabalho (São Paulo).

Assim, conseguimos perceber o quanto que a cidade de Belo Horizonte teve de especificidades em sua formação, e como a atuação do poder público foi significativa para a construção da cidade capital mineira.

\section{Considerações Finais}

Traçados urbanísticos são projetos de redesenvolvimento urbano de caráter misto, unindo políticas de uso do solo e instrumentos financeiros para promover transformações urbanísticas por meio de capitais públicos e privados. É importante salientar que o termo significa tanto a definição da política pública, quanto o estabelecimento de um projeto urbanístico específico para o redesenvolvimento de uma área urbana. Isso significa que, embora existam parâmetros gerais para o funcionamento de uma operação urbana, cada projeto contém 
elementos particulares e contextuais, constituindo não somente um lugar próprio (uma geografia urbana), mas também parâmetros urbanísticos distintos para cada experiência (SIQUEIRA, 2014).

Assim, o plano urbanístico que se formou (ou se construiu) na cidade capital mineira teve como uma das características a "negação" da possibilidade de participação política dos setores populares, contrariando, em muitos momentos os princípios de "liberdade e igualdade", ao adotar mecanismos de disciplinas sociais. Vale lembrar queBeloHorizontefoiconstruídajustamenteno contextodosurgimento da República brasileira, o que poderia levar tanto ao povo da época, quanto aos analistas de agora, a ilusão de que houve participação popular efetiva na consolidação e determinação do planejamento urbano. Entretanto, a República brasileira nascente era um cenário que não desejava ou instigava uma participação popular efetiva, de forma que ao mesmo tempo que o novo regime político despertasse entre os excluídos do governo monárquico certo entusiasmo quanto às novas possibilidades de participação (CARVALHO, 1987, p. 12), as políticas públicas deveriam assegurar que essa mesma participação não ocorresse. A intervenção pública, nas cidades em questão (e principalmente em Belo Horizonte) foi contraditória, pois mesmo trazendo resultados, do ponto de vista da recuperação urbana, era também, discriminatória e excludente, particularmente com a população removida dos grandes centros; ao mesmo tempo em que favoreceu (ainda que involuntariamente) aqueles que permaneceram e se instalaram na área central, especialmente os proprietários de imóveis.

Com as modificações sofridas nas relações de trabalho, no final do século XIX, com o fim da escravidão, as classes dominantes procuraram ajustar a população de baixa renda aos dispositivos de repressão. O governo procurou disciplinar os homens despojados de bens. Eram mecanismos mais sutis e disseminados por toda sociedade, 
como exemplo, a adaptação da população aos serviços de higiene ou mesmo os mecanismos de repressão direta como a polícia. $\mathrm{O}$ intuito era o de adaptar os novos cidadãos ao sistema político vigente (ANDRADE; MAGALHÃES, 1989).

E o estado teve um papel fundamental, pois mesmo havendo ausência de legislação trabalhista, tanto os modelos de salubridades quanto as ordens policiais, eram mecanismos disciplinadores da massa de trabalhadores urbanos. Estas estruturas estavam incumbidas de assegurar a ordem pública na cidade, o que representou submeter os espaços de moradia, lazer e mesmo o trabalho das classes populares a expedientes normativos, aliados a uma vigilância e repressão sistemática (JULIÃO, 1996, p. 85).

Desta forma, a nascente Belo Horizonte (e até mesmo as cidades do Rio de Janeiro e São Paulo) estava mais preocupada com o controle da massa social, fazendo cidadãos ativos apenas uma pequena elite dos estratos médios e altos da sociedade. A rua, mesmo prometendo lazer (o parque) e diferentes meios de se ganhar a vida, era também (e principalmente para as classes populares) um local de insegurança, onde homens pobres conviviam diariamente com a arbitrariedade e a violência da polícia no espaço público. Era uma ordem liberal, porém antidemocrática, e resistente à democratização.

Contudo, é importante ressaltar que influenciado pelos conceitos de racionalização, modernização e na excelência do regime republicano, o estado mineiro interveio racional e radicalmente no espaço em construção, se fortalecendo e conservando as forças que nele se faziam representar, através de uma redistribuição, da sociedade neste novo espaço (ANDRADE; MAGALHÃES, 1989, p. 135).

Portanto, o projeto da cidade quanto às medidas tomadas para sua completa implantação (e nisto inclui-se a remoção das favelas centrais, o a parato policial e as exigências quanto à salubridade imposta à classe socialmente desfavorecida), devem ser entendidos dentro do 
seu tempo, numa ótica de valorização do racional e para uma capital que se pretendia modelo dentro do Estado republicano de então.

\section{REFERÊNCIAS}

ANDRADE, Rodrigo Ferreira; MAGALHÃES, Beatriz de Almeida. Belo Horizonte: um espaço para a república. Belo Horizonte: UFMG, 1989.

ARRUDA, Rogério Pereira. Álbum de Bello Horizonte: signo da construção simbólica de uma cidade no início do século XX. 2000. 216 f. Dissertação (Mestrado em Comunicação Social) - Universidade Federal de Minas Gerais, Faculdade de Filosofia e Ciências Humanas, Belo Horizonte, 2000.

ARRUDA, Rogério Pereira. Cidades-Capitais imaginadas pela fotografia: La Plata (Argentina) e Belo Horizonte (Brasil), 1880-1897. 2011. 274 f. Tese (Doutorado em História) - Universidade Federal de Minas Gerais, Faculdade de Filosofia e Ciências Humanas, Belo Horizonte, 2011.

AZEVEDO, André Nunes de. A reforma Pereira Passos: uma tentativa de integração urbana. Revista Rio de Janeiro, n. 10. p.39-79, maio/ago. 2003. Disponível em: <http://www.forumrio.uerj.br/documentos/revista_10/10-AndreAzevedo.pdf $>$. Acesso em: 20 nov. 2014.

AZEVEDO, Elciene. A metrópole às avessas: cocheiros e carroceiros no progresso de invenção da "raça paulista". In: AZEVEDO, Elciene et al. Trabalhadores na cidade: cotidiano e cultura no Rio de Janeiro e em São Paulo, séculos XIX e XX. Campinas, SP: Ed. da UNICAMP, 2009. p. 63-106.

BARRETO, Abílio. Memória histórica e descritiva: (história antiga e história média). Belo Horizonte: Fundação João Pinheiro (Centro de Estudos históricos e Culturais), 1995. $2 \mathrm{v}$.

CAMPOS, Candido Malta. Os rumos da cidade: urbanismo e modernização em São Paulo. São Paulo: Ed. SENAC, 2002.

CARVALHO, Inaiá Maria Moreira de; PASTERNAK, Suzana; BÓGUS, Lúcia Machado. Transformações metropolitanas: São Paulo e Salvador. Caderno CRH, Salvador, v. 23, n. 59, maio/ago. 2010. Disponível em: <http://dx.doi.org/10.1590/ S0103-49792010000200007>. Acesso em: 11 jan. 2016.

CARVALHO, José Murilo de. Os bestializados: o Rio de Janeiro e a República que não foi. São Paulo: Cia das Letras, 1987.

COSTA, Heloísa Soares de Moura; BAPTISTA, Maria Elisa. A arquitetura silenciosa. In: CASTRIOTA, Leonardo Barci (Org.). Arquitetura da modernidade. Belo Horizonte: UFMG, 1998. p. 263-293. 
FREHSE, Fraya. Potencialidades do método regressivo-progressivo: pensar a cidade, pensar a história. Tempo Social. São Paulo, v. 13, n. 2, nov. 2001. Disponível em: <http://dx.doi.org/10.1590/S0103-20702001000200009>. Acesso em: 12 jan. 2016.

JULIÃO, Letícia. Itinerários da cidade moderna (1891-1920). In: DUTRA, Eliane de Freitas; MELLO, Ciro Flavio Bandeira de (Org.). BH: Horizontes históricos. Belo Horizonte: C/ Arte, 1996. p. 49-119.

LINHARES, Joaquim Nabuco. Mudança da Capital: apontamentos históricos. Revista do Arquivo Público Mineiro, Belo Horizonte, Ano 10, n. 1-2, p. 339-382, 1905.

LOPES, Valéria Maria Queiroz Cavalcante. Uberlândia: histórias por entre trilhas, trilhos e outros caminhos. Uberlândia: EDUFU, 2010.

OLIVEIRA, Éder Aguiar Mendes de. A imigração italiana e a organização operária em Belo Horizonte nas primeiras décadas do século XX. 2004. 93 f. Monografia (Especialização em História) - Faculdades Integradas de Pedro Leopoldo, Pedro Leopoldo, 2004.

PLAMBEL. Superintendência de desenvolvimento da Região Metropolitana de Belo Horizonte. O processo de desenvolvimento de Belo Horizonte: 1897-1970. Belo Horizonte: Plambel, 1979. 2 v, p. 3-182.

SENNETT, Richard. Carne e pedra. Rio de Janeiro: Record, 2006.

SENNETT, Richard. O declínio do homem público: as tiranias da intimidade. São Paulo: Cia das Letras, 1989.

SINGER, Paul. Desenvolvimento econômico e evolução urbana. São Paulo: Nacional, 1968.

SIQUEIRA, Marina Toneli. Entre o fundamental e o contingente: dimensões da gentrificação contemporânea nas operações urbanas em São Paulo. Cadernos Metrópole, São Paulo, v. 16, n. 32, nov. 2014. Disponível em: <http://dx.doi. org/10.1590/2236-9996.2014-3205>. Acesso em: 12 jan. 2106.

ZUCCONI, Guido. A cidade do século XIX. Tradução de Marisa Barda. São Paulo: Perspectiva, 2009. (Debates, 319). 